\title{
A REVISION OF THE SPECIES OF AGATHOMYIA OF THE EASTERN UNITED STATES.
}

\author{
By Charles W. Johnson. \\ Boston Society of Natural History, Boston, Mass.
}

Table of Species.

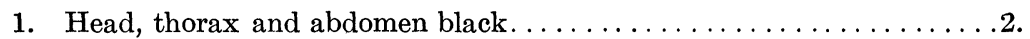
Head black, thorax and abdomen fulvous...........fulva Johns.

2. Abdomen broadly banded with yellow, scutellum yellow. pulchella Johns.

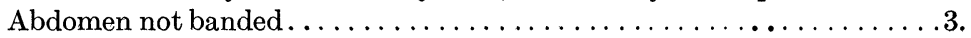

3. Thorax and abdomen both maculated with greenish white, halteres black. .............................. notata Loew.

Thorax only maculated with greenish white, halteres yellow.

divergens Loew.

Thorax and abdomen without maculations, tip of abdomen in the female cinereous, knobs of the halteres black...........talpula Loew.

Agathomyia fulva Johnson.

Callimyia fulva Johns., Psyche XV, p. 59, June, 1908.

At the time I described this and the following species, I did not have access to Verrall's work on the British Flies. A further study of these, together with the types of divergens and talpula Loew, shows that the four species are all true Agathomyia.

\section{Agathomyia pulchella Johnson.}

Callimyia pulchella Johns., Psyche XV, p. 58, June, 1908.

Since describing this species from specimens obtained at St. Johnsbury, Vt., June 27, 1906, I have collected two specimens on Mt. Ascutney, Vt., July 11, and one at Brattleboro, Vt., July 15, 1908.

\section{Agathomyia talpula Loew.}

Callomyia talpula Loew, Centur., IX, 81 (1869).

Callimyia talpula Johns., Psyche XV, p. 59 (1908). 
A female of this species was obtained at East Walpole, Mass., May 26, 1908.

Agathomyia divergens Loew.

Callomyia divergens Loew, Centur., V, 77 (1865).

Aside from the type there is a specimen in the Museum of Comparative Zoology, from the District of Columbia.

Agathomyia notata Loew.

This species has been obtained by the writer at Westville, N. J., July 2, 1893; Riverton, N. J., June 1; Auburndale, Mass., August 28; and Hanover, N. H., July 5, 1908.

Callimyia venusta Snow.

I was very much surprised to capture at Shackford Head, near Eastport, Maine, July 14, 1909, a specimen of this beautiful species, agreeing in every respect with the description. It is a true Callimyia.

Unusual Parasitic Habits of an African Ephydrid. By Dr. C. Wellman, translated from Zeitschr. wiss. Insektenbiol., Nov. 18, 1909, p. 356.

While collecting insects some time ago in West Africa, a small fly which was laying eggs on living ants (Cremastogaster sp.) attracted my attention. The fly rested on her victim, inserted her ovipositor, and then carried the seemingly perplexed and helpless ant into a small deserted spider burrow, where the ant remained until the fly larva had emerged. It was interesting to see how well the fly managed so strong a fighter as the ant, for this ant can sting severely. At first I mistook the fly for a Phorid as I knew Phora formicarum to be parasitic on Lasius niger, but on closer examination by specialists, it proved to be a member of the Ephydridae representing a new genus and species. I take this occasion to present these observations as this kind of parasitism is to my knowledge something entirely new among Diptera.

B. B. B. 

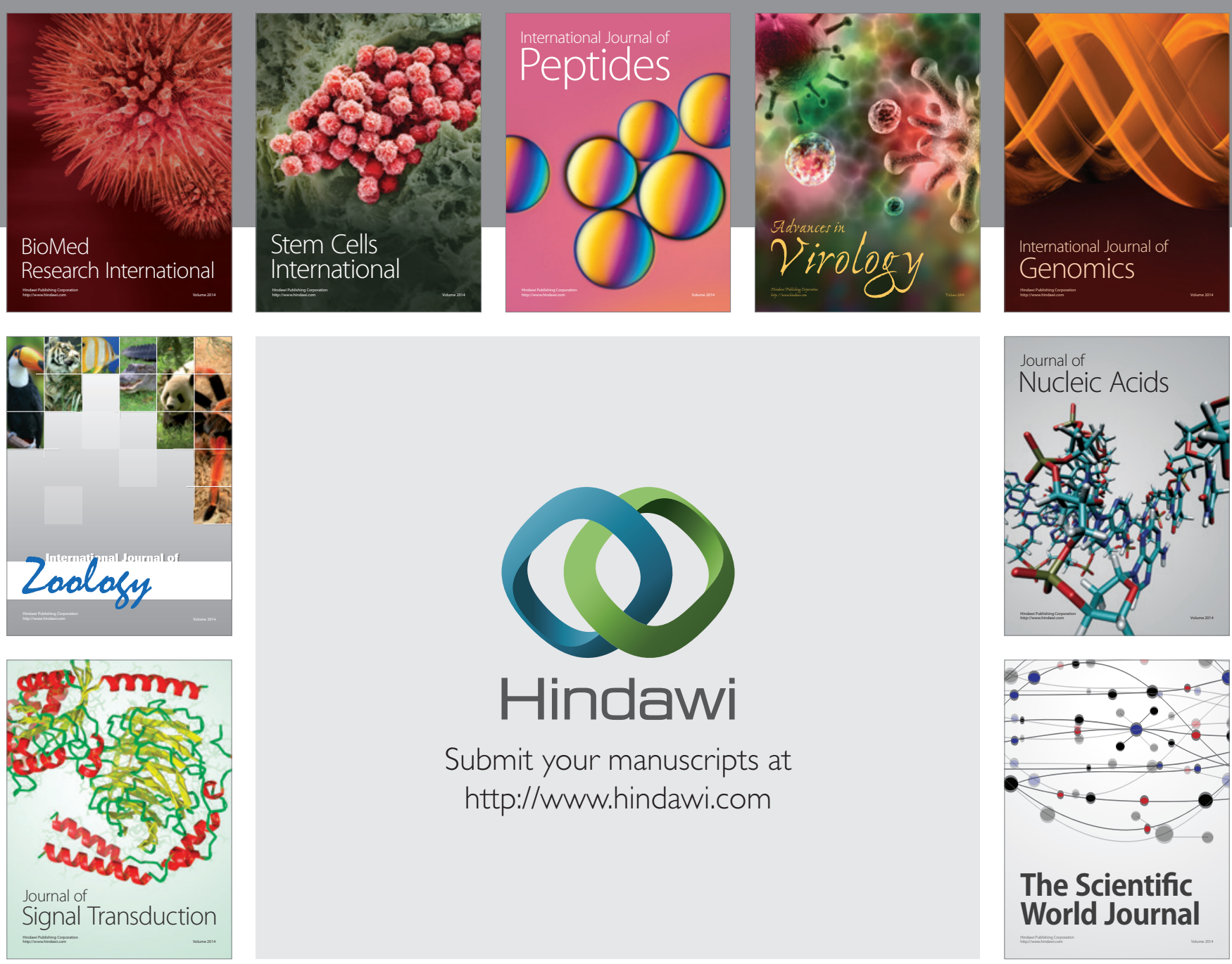

Submit your manuscripts at

http://www.hindawi.com
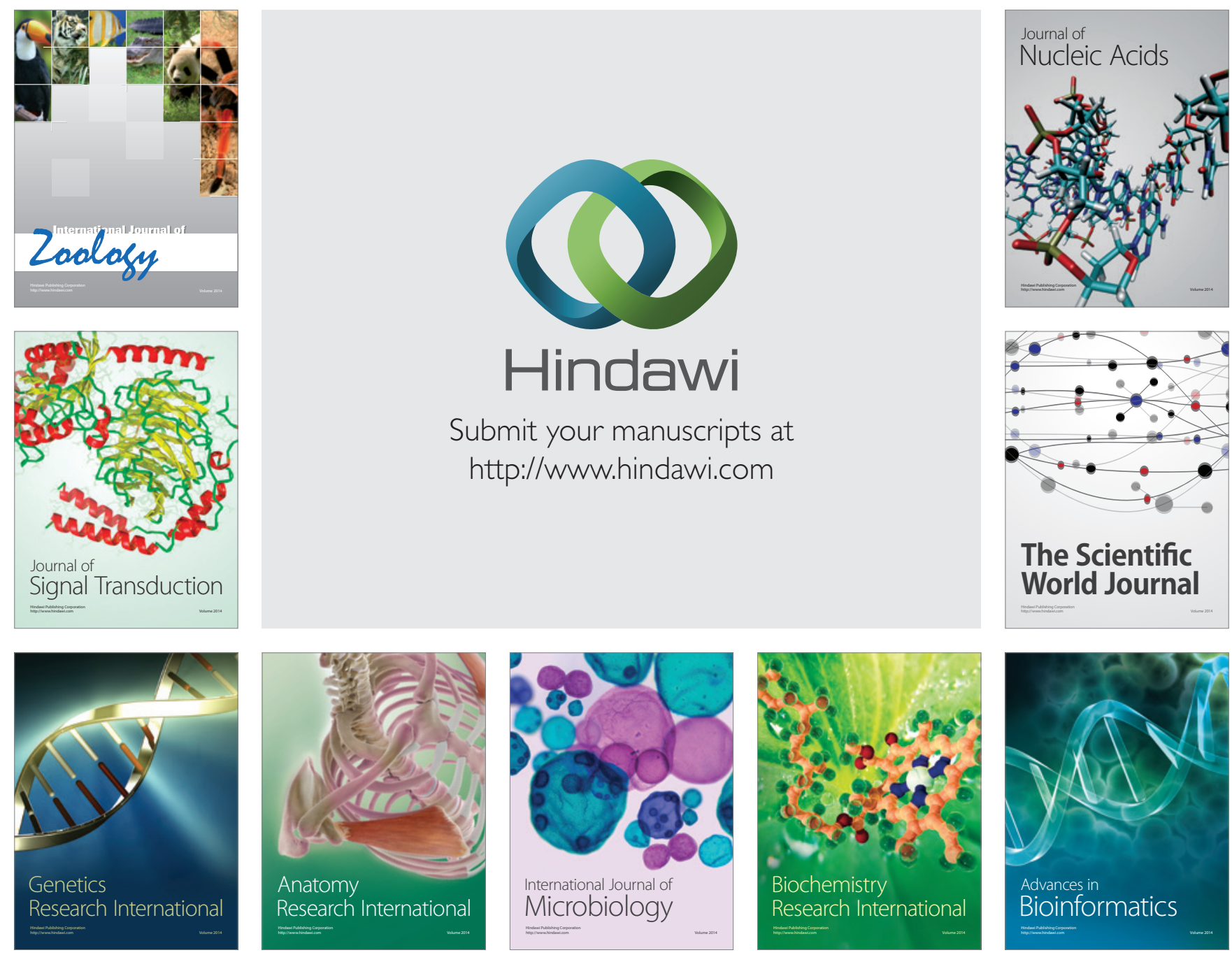

The Scientific World Journal
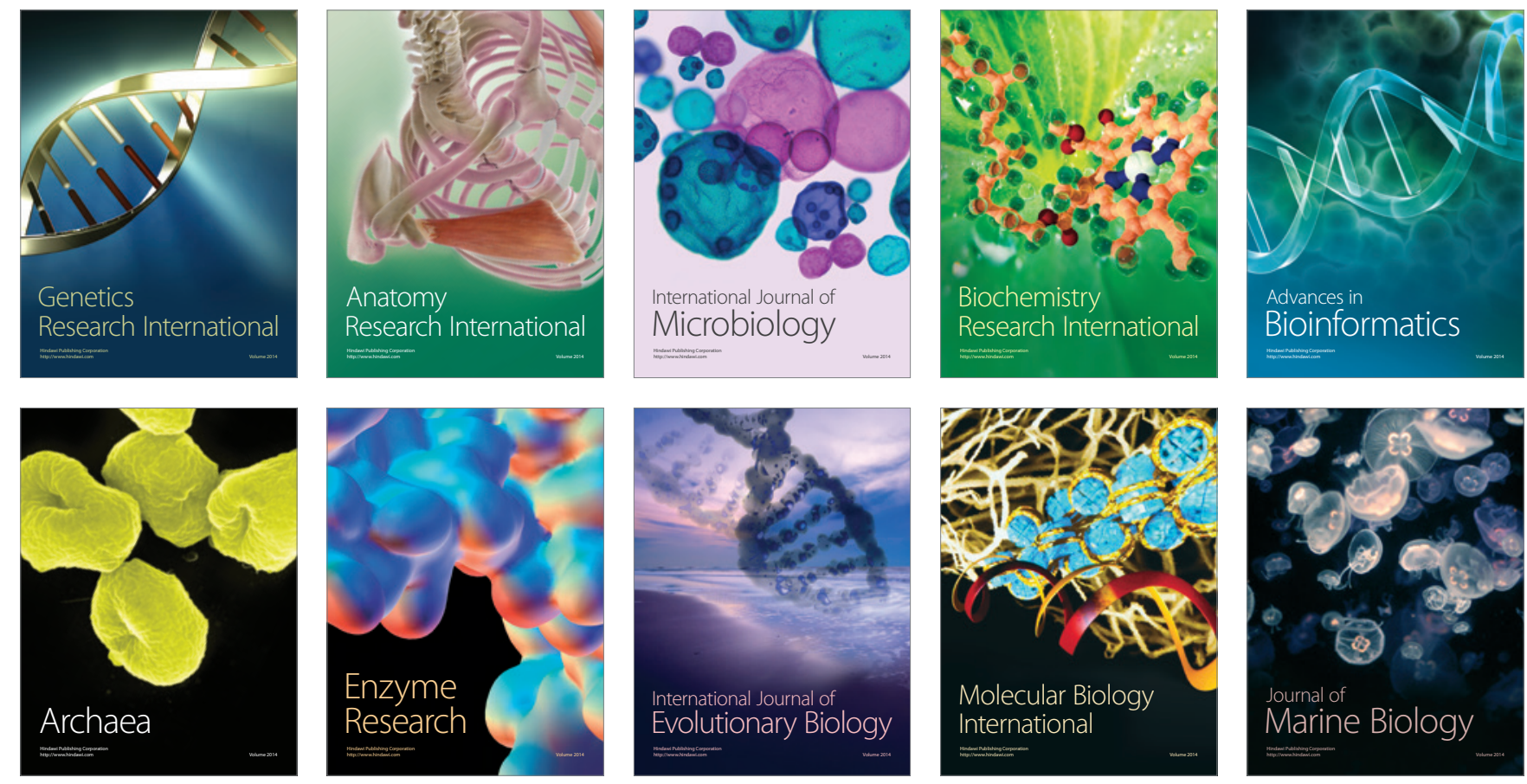